\title{
Biocompatibility and biomineralization assessment of mineral trioxide aggregate flow
}

\author{
Carlos Roberto Emerenciano Bueno ${ }^{1}$ - Ana Maria Veiga Vasques ${ }^{1}$. Marina Tolomei Sandoval Cury ${ }^{1}$. \\ Gustavo Sivieri-Araújo $^{1}$. Rogério Castilho Jacinto ${ }^{1}$. João Eduardo Gomes-Filho ${ }^{1}$ - Luciano Tavares Angelo Cintra ${ }^{1}$. \\ Eloi Dezan-Júnior ${ }^{1}$
}

Received: 24 January 2018 / Accepted: 13 March 2018 / Published online: 23 March 2018

(C) Springer-Verlag GmbH Germany, part of Springer Nature 2018

\begin{abstract}
Objective Evaluate, in vivo, the biocompatibility via subcutaneous inflammatory tissue response and mineralization ability of the new MTA Flow compared to MTA Angelus and ProRoot MTA.

Materials and methods Forty male Wistar rats were assigned and received subcutaneous polyethylene tube implants containing the test materials and a control group with empty tube ( $n=10$ animals/group). After days $7,15,30$, and 60 , the animals were euthanized and the polyethylene tubes were removed with the surrounding tissues. Inflammatory infiltrate and thickness of the fibrous capsule were histologically evaluated. Mineralization was analyzed by Von Kossa staining and under polarized light. Data were analyzed via Kruskal-Wallis and Dunn's test with a significance level of 5\%.

Results MTA Angelus induced the mildest reaction after $7(P>.05)$ and 15 days $(P<.05)$ followed by MTA Flow, both cements achieving mild inflammatory reaction after 15 days. ProRoot MTA induced a severe inflammation on day 7 and was reducing after day $15(P>.05)$. No difference was observed after days 30 or $60(P>.05)$. Von Kossa staining and birefringent structures were positive to all materials.

Conclusions At the end of the experiment, the novel MTA Flow showed biocompatibility and induced biomineralization in all time periods.

Clinical relevance The final consistence obtained in MTA Flow may facilitate several procedures, indicating that the MTA Flow has a promising application in endodontics.
\end{abstract}

Keywords Biocompatibility $\cdot$ Biomineralization $\cdot$ Inflammation $\cdot$ Mineral trioxide aggregate

\section{Introduction}

Biocompatibility and capacity to induce biomineralized tissue formation are important requirements for sealing materials that will be in contact with tissue [1].

The biocompatibility evaluation in rat model may be assessed by different methodologies such as pulpotomy [2], subcutaneous implantation [3], cell viability [4], or even in dental alveolus [5]. The implantation of these materials into the subcutaneous tissue of rats is considered a standardized

Eloi Dezan-Júnior

dezan@ foa.unesp.br

1 Department of Endodontics, Araçatuba School of Dentistry, Sao Paulo State University (Unesp), R: José Bonifácio, 1193, Vila

Mendonça, Araçatuba/São Paulo 16015-050, Brazil
[6], common, and valid test for biocompatibility [7], analyzing the inflammatory tissue response through $\mathrm{HE}$ staining $[3-5,8$, 9] within time periods of the recommended standard practices for biological evaluation of dental materials [10].

The mineral trioxide aggregate (MTA), a Portland cementderived calcium silicate-based hydraulic material [11], was developed to seal communication between teeth and the periodontium, in pathologic or iatrogenic root perforations $[12,13]$. Numerous studies confirmed its effectiveness as a biocompatible material, inducing the formation of mineralized tissue, besides the antimicrobial activity. These excellent biological properties are attributed to its alkaline $\mathrm{pH}$ and calcium ion release capacity, maintaining a high $\mathrm{pH}$ [14-16]. The hydrophilic nature of the MTA particles allows its use even in the presence of moisture, once the main components are tricalcium and dicalcium silicate, tricalcium aluminate, tricalcium oxide, and radiopacifying agents, such as bismuth oxide [17]. 
MTA Angelus (Angelus Indústria de Produtos Odontológicos S/A, Londrina, PR, Brazil) and ProRoot MTA (Tulsa Dental Products, Tulsa, OK, USA) are MTA cements with proven biological and physical-chemical properties, both known for their favorable tissue response and capability of forming mineralized tissue $[8,18]$.

However, the poor working properties of MTA-like cements results in a paste hard to manipulate and to deliver [19]. Considering the importance of the ideal flow ability that endodontic cements should present reducing the difficulty of handling [20], high plasticity cements were developed with the aim of improving these characteristic.

Recently released, the MTA Flow (Ultradent Products Inc., South Jordan, UT) consists of a gray powder of di- and tricalcium silicate, bismuth oxide as radiopacifier, and a liquid vehicle composed of a water soluble silicone-based gel [21]. According to the manufacturer, the gel provides a higher plasticity, improving handling and its insertion, which may facilitate the use in various procedures: a thick consistency for pulp capping, pulp chamber perforation, and pulpotomy; a thin consistency for resorption, apexification, and apical plug; or a putty consistency for root end filling [22]. The manufacturer also claims that unlike other MTA cements, which use water and have a coarse sandy consistency, MTA Flow cement has a creamy and homogeneous characteristic after mixing. The presentation of this material seems to be innovative in relation to the other cements available. However, as a new cement, there are no published studies concerning its biological properties or ability to induce the formation of hard tissue.

Therefore, the aim of the present study was to evaluate MTA Flow, analyzing the in vivo reaction of subcutaneous tissue of rats, and its ability to induce mineralization, assessed by von Kossa staining and presence of structures birefringent under polarized light. MTA Angelus and ProRoot MTA were used for comparison.

\section{Materials and methods}

This study was approved by the institutional Ethics Committee on the Use of Animals at UNESP-Universidade Estadual Paulista (São Paulo, Brazil) and conducted in accordance with relevant guidelines (CEUA protocol 00225-2017).

\section{In vivo study}

Subcutaneous implant Forty male 4 to 6-month-old Wistar rats, weighing 250-280 g, were used in the study. The animal sample size was based on previous studies that used the same methodology to assess biocompatibility and biomineralization in subcutaneous tissue of rats $[3-5,8,23]$. The animals were housed in temperature-controlled rooms and were provided with water and food ad libitum.

One hundred and sixty polyethylene tubes (Abbott Laboratories of Brazil, Sao Paulo, SP, Brazil) were prepared according to previous studies $[8,24]$ and filled with the tested cements. ProRoot MTA and MTA Angelus were spatulated according to the manufacturer's specification and inserted into the tubes with the aid of a lentullo spiral. MTA Flow was manipulated and inserted into a proper syringe and directly inserted into the polyethylene tubes. Therefore, all polyethylene tubes were completely filled, standardizing the same amount of cement for all experimental groups. Forty extra polyethylene empty tubes were used as controls, totaling 160 tubes in the experiment.

The surgical procedure was performed following previous studies $[3,8,23,24]$. After administration of xylazine $(10 \mathrm{mg} /$ kg Rhobifarma Indústria Farmacêutica Ltda, Hortolândia, Brazil) and ketamine (25 mg/kg União Química Farmacêutica Nacional S/A, São Paulo, Brazil) intramuscular anesthesias, the backs of the animals were shaved, antisepsis was obtained with $5 \%$ iodine solution, and a $2-\mathrm{cm}$ incision was formed in a head-tail orientation with no. 15 Bard-Parker blade (BD, Franklin Lakes, NJ). The skin was reflected to create two pockets on the right side (upper and lower) and another two pockets on the left side of the incision (upper and lower), totalizing four experimental sites. Three polyethylene tubes, containing the cements, and an empty tube, as the control, were implanted in the dorsal region of each animal in the created pockets in opposite directions (upper right, upper left, lower right, and lower left), and the skin was closed with a 4/0 silk suture (Johnson \& Johnson Produtos Prossionais Ltda, São José dos Campos, Brazil).

After 7, 15, 30, and 60 days, the animals were killed by an anesthetic overdose. Polyethylene tubes, with the surrounding tissues, were removed and fixed in $10 \%$ formalin solution at a $\mathrm{pH}$ 7.0. The fixed specimens were processed and embedded in paraffin and serially sectioned into $5-\mu \mathrm{m}$ cuts for staining with hematoxylin-eosin and $10-\mu \mathrm{m}$ cuts for staining with the von Kossa technique, used to observe mineralization as it darkly stains mineralized structures. Some slices were kept unstained for examination under polarized light to observe the presence of birefringent structures (Graph 1).

Histologic analysis was performed by a single calibrated operator in a blinded manner under $\times 400$ light microscopy (DM 4000 B; Leica, Wetzlar, Germany). Tissue reactions at the open end of the tubes were scored according to previous studies [3-5, 8, 23] as follows: 0 , few inflammatory cells or no reaction; 1 , less than 25 cells and mild reaction; 2 , between 25 and 125 inflammatory cells and moderate reaction; and 3, 125 or more inflammatory cells and severe reaction. Fibrous capsules were considered thin when $<150 \mu \mathrm{m}$ and thick when $>$ $150 \mu \mathrm{m}$, as exemplified in Fig. 1. The Hematoxylin-Eosin staining allowed the evaluation of the contact area between 


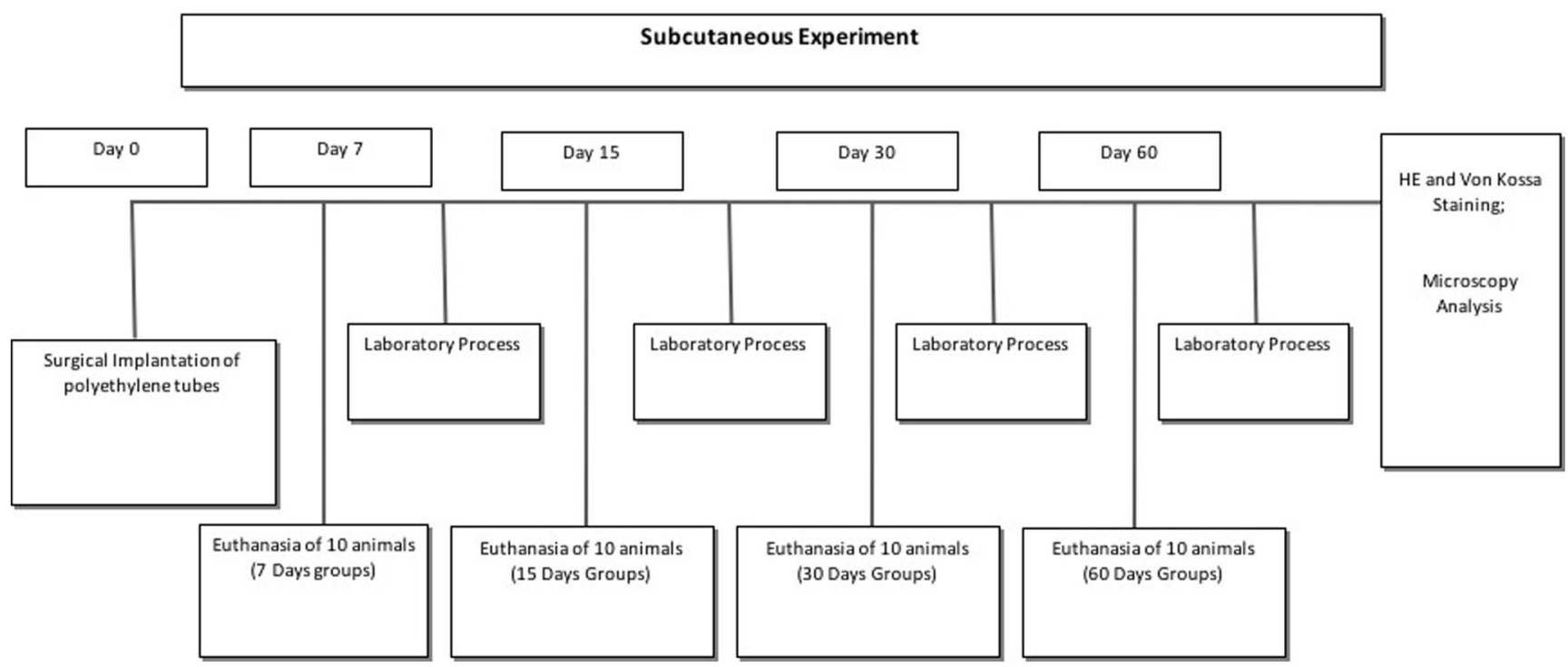

Graph 1 Study graphical outline, showing the experiment protocol at day 0 (subcutaneous implantation), days 7, 15, 30, and 60 (euthanasia, followed by the laboratory process: tube removal with surrounding

the subcutaneous tissue and the tested material (at the lower center of the polyethylene tube) and one of the scores was attributed, classifying the tissue response as mild, moderate, or severe for each experimental time period of $7,15,30$, and 60 days.

Calcification was recorded as positive or negative by Von Kossa staining and present or absent under PL [3, 8].

Statistical analysis Data were submitted to statistical analysis using the Sigma Plot (version 12.0, Systat Software Inc., CA) software program. The Kruskal-Wallis test followed by the Dunn test was performed for the nonparametric data; $P<.05$ was considered significant. tissue and paraffin embedding), samples staining and microscopy analysis.

\section{Results}

\section{The control group}

A moderate chronic inflammatory infiltrate (median score 2) was observed at the first two experimental periods (Table 1), on days 7 and 15 (Fig. 2(A,a, B,b)). The inflammatory reaction, with lymphocytes and macrophages, was present in the thick fibrous capsule. After 30 and 60 days (Fig. 2(C,c, D,d)), the fibrous capsule became thin, with few inflammatory cells (median score 1). The mineralization was negative for Von Kossa and no birefringent structures were present under PL at all time periods, as observed in Table 2 and Fig. 3(A,a-D,d).

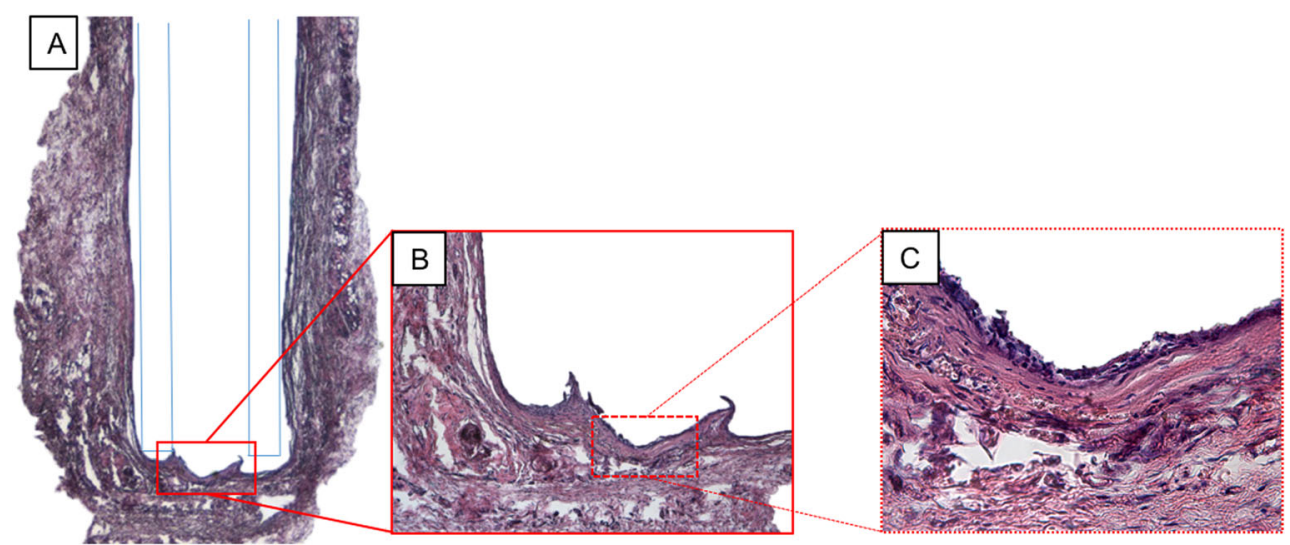

Fig. 1 Example of subcutaneous tissue in the MTA Flow group (60 days after implantation) situated around the polyethylene tube, after the tube removal for the paraffin embedding process, evidencing the area of analysis in the tube opening in $\times 25$ magnification $(\mathrm{A})$. The contact area in the center of the tube opening in $\times 100(\mathrm{~B})$; and the inflammatory response in the tube opening in $\times 400(\mathrm{C})$, where it is possible to observe fibroblasts and a few inflammatory cells, mainly composed by lymphocytes (less than 25), characterizing a mild inflammatory reaction (score 1) 
Table 1 Percentage of samples in each group categorized according to the inflammatory score, the median and the thickness of fibrous capsule in the four experimental periods

\begin{tabular}{lrrrrrl}
\hline & & Score $(\%)$ & & & Median & Capsule \\
\hline 7 days & 0 & 1 & 2 & 3 & & \\
Control & 0 & 0 & 100 & 0 & 2 & Thick \\
MTA Flow & 0 & 20 & 80 & 0 & 2 & Thick \\
MTA Angelus & 0 & 40 & 60 & 0 & 2 & Thick \\
ProRoot MTA & 0 & 30 & 20 & 50 & 3 & Thick \\
15 days & & & & & & \\
Control & 0 & 0 & 100 & 0 & 2 & Thick \\
MTA Flow & 0 & 70 & 30 & 0 & 1 & Thin \\
MTA Angelus & 0 & 100 & 0 & 0 & 1 & Thin \\
ProRoot MTA & 0 & 30 & 40 & 30 & 2 & Thick \\
30 days & & & & & & \\
Control & 0 & 100 & 0 & 0 & 1 & Thin \\
MTA Flow & 0 & 100 & 0 & 0 & 1 & Thin \\
MTA Angelus & 0 & 100 & 0 & 0 & 1 & Thin \\
ProRoot MTA & 0 & 80 & 20 & 0 & 1 & Thin \\
60 days & & & & & & \\
Control & 20 & 80 & 0 & 0 & 1 & Thin \\
MTA Flow & 0 & 100 & 0 & 0 & 1 & Thin \\
MTA Angelus & 0 & 100 & 0 & 0 & 1 & Thin \\
ProRoot MTA & 0 & 100 & 0 & 0 & 1 & Thin \\
\hline & & & & & &
\end{tabular}

\section{MTA Angelus}

The inflammatory infiltrate was considered moderate after 7 days (median score 2) and reduced to a mild inflammation (median score 1$)$ from day $15(P<.05)$ to 60 , as observed in Fig. 2(E,e-H,h) and Table 1. The fibrous capsule near the tube opening was thick only on day 7 (Fig. 2(E,e)) and became thin after 15 days and continued until the end of the experimental time periods (Fig. 2(F,f-H,h)). Granulations birefringent to PL and Von Kossa-positive staining were observed near the tube opening at all time periods (Fig. 3(E,e-H,h) and Table 2).

\section{MTA Flow}

Only on day 7, a moderate inflammatory cell infiltration (median score 2), comprising lymphocytes and macrophages, was present in the thick fibrous capsule (Fig. 2(I,i); Table 1). After 15,30 , and 60 days, the intensity of the inflammation was reduced (median score $1 ; P>.05$ ) and the fibrous capsule was thin, similar to the control group (Fig. 2(J,j-L,l). The presence of granulations birefringent under PL and Von Kossa-positive stains was observed in all time periods (Fig. 3(I,i-L,l) and Table 2).

\section{ProRoot MTA}

Although a severe inflammatory infiltrate was observed (median score 3$)$ after 7 days $(P>.05)$, it was notable that almost half of the specimens achieved a moderate and mild inflammation (median score 2 and 1, respectively), both in a thick fibrous capsule (Fig. 2(M,m) and Table 1). After 15 days, the inflammation was reduced (median score 2) but the fibrous capsule remained thick (Table 1). Only after 30 and 60 days, the inflammatory infiltrate was considered mild (median score $1 ; P>.05$ ) and with a thin fibrous capsule in both periods (Fig. $2(\mathrm{O}, \mathrm{o}, \mathrm{P}, \mathrm{p})$ and Table 1$)$, same result as the control group. The biomineralization ability was observed in all time periods, with structures darkly stained by the Von Kossa technique and the presence of birefringent structures under PL was also observed (Fig. 3(M,m-P,p) and Table 2).

\section{Comparison among groups}

Data were compared for each time period (Tables 1 and 2). After 7 days, the control group showed a median score 2, with a thick fibrous capsule. ProRoot MTA showed a severe inflammation (median score 3) after 7 days, with a thick fibrous capsule. After 15 days, it was possible to observe a reduction on the inflammatory infiltrate regarding MTA Angelus $(P<.05)$ and MTA Flow, which induced a mild inflammation (median score 1) in a thin fibrous capsule. The control group remained with a thick fibrous capsule and the moderate inflammation after 15 days, same result as the ProRoot MTA. After 30 and 60 days, all groups presented a mild inflammatory infiltrate (median score 1), restricted to a thin fibrous capsule, without statistical difference $(P>.05)$.

Regarding the biomineralization, with exception of the control group, all cements induced the formation of mineralized tissue in all experimental periods, confirmed by the presence of structures darkly stained by the Von Kossa technique (Fig. 3(A-P); Table 2) and the birefringent structures observed under polarized light (Fig. 3(a-p); Table 2).

Fig. 2 Representative images of subcutaneous tissue reactions in the experimental groups. The control group (A,a-D,d), at 7 and 15 days: thick fibrous capsule and moderate inflammatory reaction $(\mathrm{A}, \mathrm{a}, \mathrm{B}, \mathrm{b})$; after 30 days: reduction in the thickness of the fibrous capsule and mild inflammatory reaction $(\mathrm{C}, \mathrm{c})$ and $(\mathrm{D}, \mathrm{d})$ thin fibrous capsule and mild inflammatory reaction (day 60). MTA Angelus (E,e-H,h); at 7 days: $(\mathrm{E}, \mathrm{e})$ thick fibrous capsule formation and moderate inflammatory cell infiltration; after 15,30 , and 60 days: $(\mathrm{F}, \mathrm{f}-\mathrm{H}, \mathrm{h})$ reduction in the thickness of the fibrous capsule formation and mild inflammatory cell infiltration. MTA Flow (I,i-L,l), at 7 days: $(\mathrm{I}, \mathrm{i})$ moderate cell infiltration in a thick fibrous capsule; after 15,30 , and 60 days: $(\mathrm{J}, \mathrm{j}-\mathrm{L}, 1)$ mild inflammatory reaction in a thin fibrous capsule. ProRoot MTA $(\mathrm{M}, \mathrm{m}-$ P,p), at 7 days: $(M, m)$ severe inflammatory infiltrate in a thick fibrous capsule; at 15 days: $(\mathrm{N}, \mathrm{n})$ moderate inflammation in a thick fibrous capsule; after 30 and 60 days: $(\mathrm{O}, \mathrm{o}, \mathrm{P}, \mathrm{p})$ mild inflammatory cell infiltration and a thin fibrous capsule. Hematoxylin-eosin staining. Original magnification: $(\mathrm{A}-\mathrm{P}) \times 100,(\mathrm{a}-\mathrm{p}) \times 400$ 


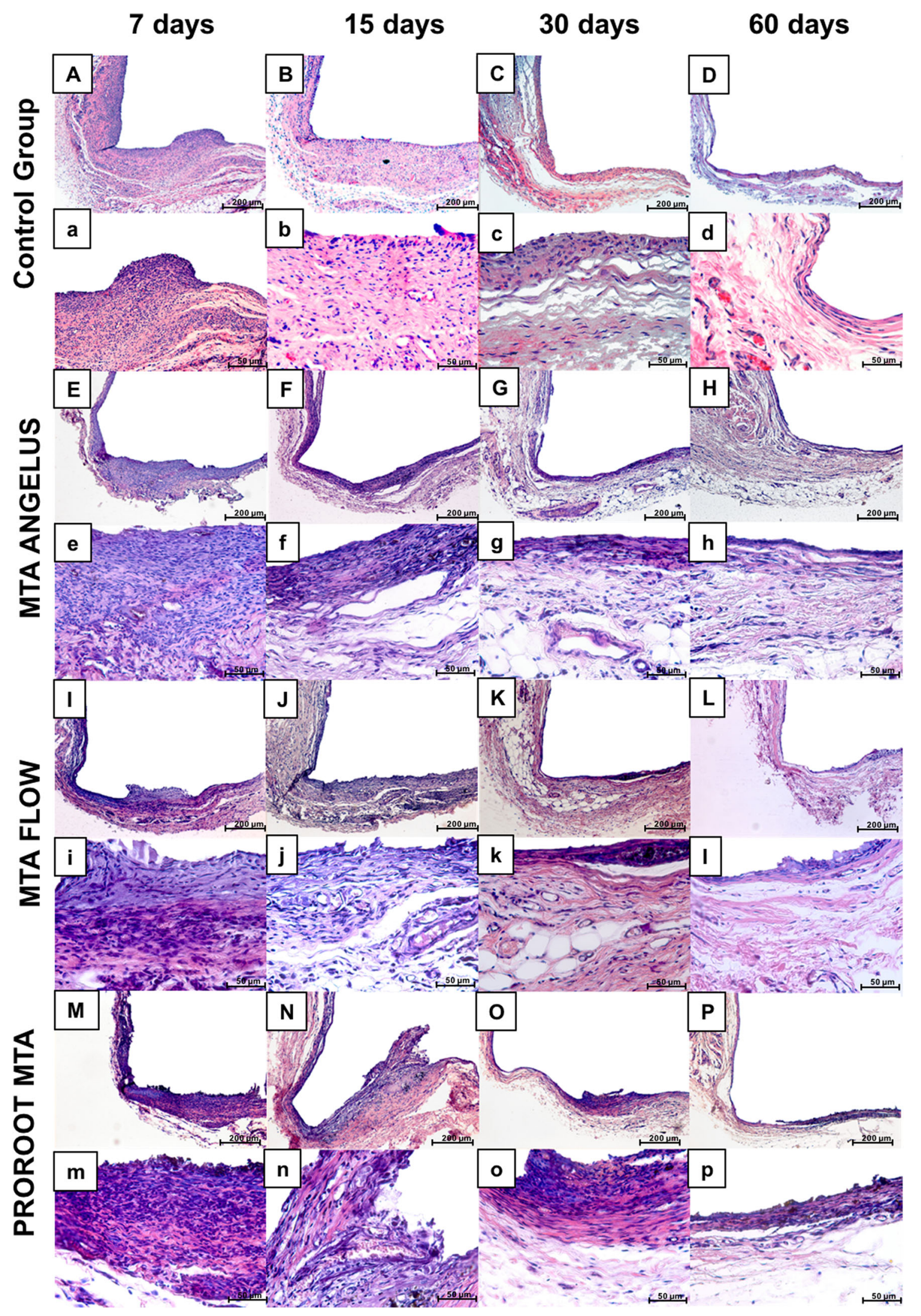


Table 2 Percentage of samples in each group categorized according to Von Kossa-positive to mineralization and presence of birefringents crystals under polarized light

Von Kossa (\%)

Polarized light (\%)

\begin{tabular}{lrr}
$\quad 7$ days & & \\
Control & 0 & 0 \\
MTA Flow & 100 & 100 \\
MTA Angelus & 100 & 100 \\
ProRoot MTA & 100 & 100 \\
15 days & & \\
Control & 0 & 0 \\
MTA Flow & 100 & 100 \\
MTA Angelus & 100 & 100 \\
ProRoot MTA & 100 & 100 \\
30 days & & \\
Control & 0 & 0 \\
MTA Flow & 100 & 100 \\
MTA Angelus & 100 & 100 \\
ProRoot MTA & 100 & 100 \\
60 days & & \\
Control & 0 & 0 \\
MTA Flow & 100 & 100 \\
MTA Angelus & 100 & 100 \\
ProRoot MTA & 100 & \\
\hline
\end{tabular}

\section{Discussion}

This research showed the MTA Flow was biocompatible and induced biomineralization, as well as the MTA Angelus and the ProRoot MTA. According to the American Association of Endodontists, a new material should be biologically and clinically studied before its use [25], since materials that will be in close contact with the periapical tissues should exhibit biocompatibility and the ability to induce the formation of mineralized tissue [26]. The rat model for subcutaneous implantation is widely used as one of the pre-clinical research tests for biocompatibility, when facing new materials [6, 7, 27].

The choice of using MTA Angelus and the ProRoot MTA as a positive control was due to several studies concerning biocompatibility and biomineralization. In the present study, the groups showed a moderate initial inflammatory response, reducing over time as the fibrous capsule became thin, corroborating previous findings [9, 24, 28-31]. This initial inflammatory reaction is due to the surgical procedure, and the normal reaction form the tissue when facing a subcutaneous implant, as well as for the MTA Angelus and the MTA Flow group. It is normal to observe an initial inflammatory reaction when using MTA-like cements, because the alkalinity damage provoked on tissues but it is also important to state that the biocompatibility of a material is achieved if the initial inflammatory reaction reduces over time, to a not significant level $[32,33]$.

The biocompatibility and bioactivity of MTA begins with its setting reaction. The hydration of mineral oxide compounds produces calcium silicate hydrate and calcium hydroxide, which after dissociation, continuously releases Ca ions, providing a high alkalinity environment and inducing the formation of mineralized tissue [34]. The ions $\mathrm{Ca}$, originating from the MTA dissociation, interacts with $\mathrm{P}$ ions in body fluids resulting in the formation of calcium phosphate crystalline structures on the materials' interfacial surfaces, which is an amorphous form of calcium phosphate and/or carbonate apatite [35-38].

The earliest MTA cements exhibited a difficult handling and consequently difficult delivering [39] leading to the constant search of new formulations to improve flowability, combining enhanced handling, mechanical and biological properties $[40,41]$. This innovation in the vehicle used to achieve a higher plasticity type of MTA has been recently studied, showing biocompatibility and inducing biomineralization [8].

A recent study regarding the chemical-physical properties and the apatite-forming ability of the MTA Flow reported alkalinizing capability, low solubility, good radiopacity and the ability to form calcium phosphate deposits [42]. Until now, there are no studies in the literature concerning the biological properties of the MTA Flow. The manufacturer claims that this novel MTA-repair cement combined with the water silicone-based gel improves the handling of the cement and can be adapted depending on the procedure, since after mixing, the MTA Flow achieves a consistency that passes through a syringe, facilitating insertion [22].

Previous reports that used the implantation of bioactive materials in subcutaneous tissue of rats described the formation of a mineralized layer, darkly stained by the Von Kossa technique [3, 34]. In the present study, the biomineralization ability of MTA Flow was detected by the presence of structures birefringent to polarized light and von Kossa-positive staining, also observed in the MTA Angelus and ProRoot MTA. According to Hinata [11], the presence of Von Kossapositive structures is in accordance with a production of $\mathrm{Ca}$ and $\mathrm{P}$ surface precipitates and a $\mathrm{Ca}$ - and $\mathrm{P}$-rich layer at the interface between material and tissue, supporting the ability of calcium silicate-based materials to promote biomineralization after contact with connective tissue. Reinforcing these findings, Guimaraes et al. [42] reported through an energydispersive X-ray (EDX) analysis that the calcium (Ca) and phosporous (P) ratios of MTA Flow were higher in

Fig. 3 Biomineralization in the experimental groups in Von Kossa (A-P) and under polarized light $(\mathrm{a}-\mathrm{p})$ under $\times 100$ magnification; control at 7 , 15,30 , and 60 days: absence of dystrophic calcification (A-D) and absence of birefringent structures under polarized light $(\mathrm{a}-\mathrm{d})$ in all time periods; MTA Angelus at 7, 15, 30, and 60 days: Von Kossa-positive staining $(\mathrm{E}-\mathrm{H})$ and granulations birefringent to PL $(\mathrm{e}-\mathrm{h})$ were observed near the tube opening at all time periods; MTA Flow at 7, 15, 30, and 60 days: presence of Von Kossa-positive staining (I-L) and birefringent structures under PL (i-1) in all periods; ProRoot MTA at 7, 15, 30, and 60 days: Von Kossa-positive staining (M-P) and birefringent structures under polarized light $(\mathrm{m}-\mathrm{p})$ in all experimental periods 

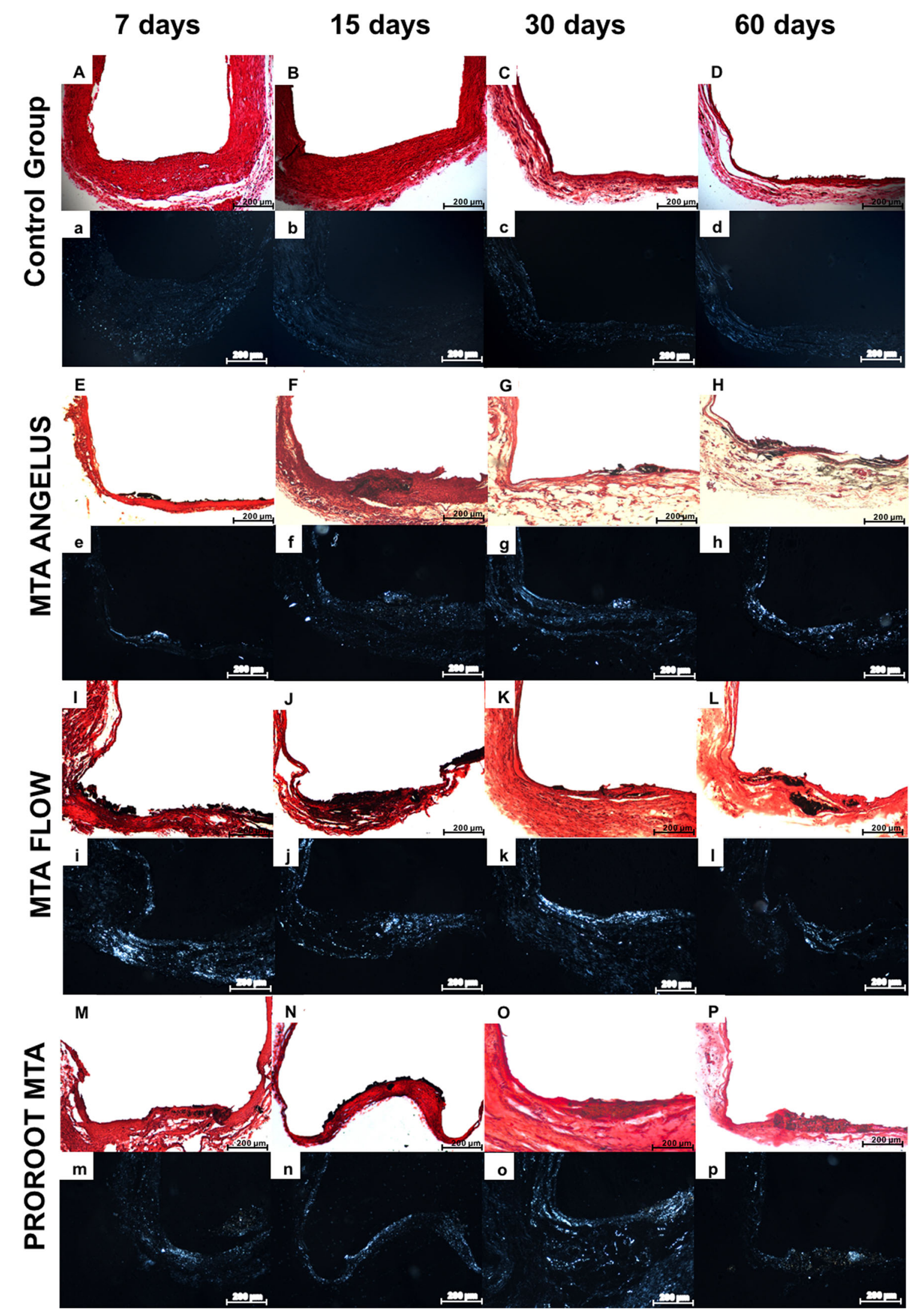

60 days 
comparison with MTA Angelus, possibly related to the gel vehicle, which increases the resistance of particles to external water.

Another important factor observed in our laboratory experience was the different consistency between the types of MTA used in the study during the mixing. Although the particle size was not analyzed in this research, the granulations in MTA Angelus and ProRoot MTA were apparently more thick, hindering the cement handling, while the MTA Flow showed a thinner composition of the powder, which, in addition of the water-based gel, facilitated the procedure, corroborating previous findings [42]. The manufacturer claims that the smooth consistency achieved with MTA Flow cement is due not only to the proprietary gel medium, but mainly also to the ultrafinefined powder, which differs from others MTA cements available in the market [22]. The potential influence of particle size might increase the reactivity of the dicalcium and tricalcium silicate particles, since the geometry of small MTA particles enables entering into open dentin tubules, which could be an important mechanism to enhance the sealing ability and even improving the handling of MTA-like cements [43].

Within the limits of this study in the rat model, the novel MTA Flow showed biocompatibility and the ability to form biomineralizated tissue, representing an alternative to the conventional MTA, with a final consistency that could facilitate its clinical use. Since this is the first study evaluating biological properties, additional research is necessary to confirm the present findings.

Acknowledgments The authors would like to thank Ultradent Products, Inc. for providing the MTA Flow used in this study.

Funding This research was supported by Coordenação de Aperfeiçoamento de Pessoal de Nível Superior (CAPES), Brazil.

\section{Compliance with ethical standards}

Conflict of interest The authors declare that they have no conflict of interest.

Ethical approval All applicable international, national, and/or institutional guidelines for the care and use of animals were followed. Before any procedure, the project was approved by Faculdade de Odontologia de Araçatuba, UNESP, Animal Ethical Committee (CEUA protocol 00225-2017).

Informed consent For this type of study, formal consent is not required.

\section{References}

1. Mori GG, Teixeira LM, de Oliveira DL et al (2014) Biocompatibility evaluation of biodentine in subcutaneous tissue of rats. J Endod 40: 1485-1488

2. Edanami N, Yoshiba N, Ohkura N, Takeuchi R, Tohma A, Noiri Y, Yoshiba K (2017) Characterization of dental pulp myofibroblasts in rat molars after pulpotomy. J Endod 43:1116-1121
3. Bueno CRE, Valentim D, Marques VAS, Gomes-Filho JE, Cintra LT, Jacinto RC et al (2016) Biocompatibility and biomineralization assessment of bioceramic-, epoxy-, and calcium hydroxide-based sealers. Braz Oral Res 30(1):81

4. Cintra LTA, Benetti F, Queiroz IOA, Ferreira LL, Massunari L, Bueno CRE, Oliveira SHPO, Gomes-Filho JE (2017) Evaluation of the cytotoxicity and biocompatibility of new resin epoxy-based endodontic sealer containing calcium hydroxide. J Endod 43:2088-2092

5. Bueno CRE, Lopes GA, Valentim D, Marques VAS, Vasques AMV, Cury MT, Sivieri-Araujo G, Jacinto RDC, Cintra LTA, Dezan-Junior E (2017) Mixing failures of endodontic sealers: an in vivo biocompatibility study. Braz Dent Sci 20(4):85-92

6. ISO 10993-6. Biological evaluation of medical devices. Part 6: Tests for local effects after implantation International Standard Norm, Porto, Portugal (2007)

7. Olsson B, Sliwkowsky A, Langeland K (1981) Subcutaneous implantation for the biological evaluation of endodontic materials. $\mathrm{J}$ Endod 7:355-369

8. Cintra LTA, Benetti F, Queiroz IOA, Lopes JMA, Sandra Oliveira SHP, Sivieri Araujo G, Gomes-Filho JE (2017) Cytotoxicity, biocompatibility, and biomineralization of the new high-plasticity MTA material. J Endod 43:774-778

9. Cintra LT, Ribeiro TA, Gomes-Filho JE et al (2013) Biocompatibility and biomineralization assessment of a new root canal sealer and rootend filling material. Dent Traumatol 29:145-150

10. Federation Dentaire Internationale (1980) Recommended standard practices for the biological evaluation of dental materials. Int Dent $\mathrm{J}$ 30:174-176

11. Hinata G, Yoshiba K, Han L, Edanami N, Yoshiba N, Okiji T (2017) Bioactivity and biomineralization ability of calcium silicate-based pulp-capping materials after subcutaneous implantation. Int Endod J 50:40-45

12. Torabinejad M, Watson TF, PittFord TR (1993) Sealing ability of a mineral trioxide aggregate when used as a root end filling material. J Endod 19:591-595

13. Lee SJ, Monse FM, Torabinejad M (1993) Sealing ability of a mineral trioxide aggregate for repair of lateral root perforations. J Endod 19:541-544

14. Sarkar NK, Caicedo R, Ritwik P, Moiseyeva R, Kawashima I (2005) Physicochemical basis of the biologic properties of mineral trioxide aggregate. J Endod 31(2):97-100

15. Tanomaru-Filho M, Torres FFE, Bosso-Martelo R, ChávezAndrade GM, Bonetti-Filho I, Guerreiro-Tanomaru JM (2017) A novel model for evaluating the flow of endodontic materials using micro-computed tomography. J Endod 43:796-800

16. Zarrabi MH, Javidi M, Jafarian AH, Joushan B (2010) Histologic assessment of human pulp response to capping with mineral trioxide aggregate and a novel endodontic cement. J Endod 11:1778-81. 12

17. Parirokh M, Torabinejad M (2010) Mineral trioxide aggregate: a comprehensive literature review-part I: chemical, physical, and antibacterial properties. J Endod 36:16-27

18. Camilleri J (2008) The chemical composition of mineral trioxide aggregate. J Conserv Dent 11:141-143

19. Canadas PS, Berastegui E, Gaton-Hernandez P et al (2014) Physicochemical properties and interfacial adaptation of root canal sealers. Braz Dent J 25:435-441

20. Duarte MA, Ordinola-Zapata R, Bernardes RA et al (2010) Influence of calcium hydroxide association on the physical properties of AH Plus. J Endod 36:1048-1051

21. Endo-Eze MTA FLOW Gel Safety Data Sheet (2017). Avaliable at: www.ultradent.com/en-us/Dental-Products-Supplies/Endodontics/ MTA-repair-cement/endo-eze-MTAflow-mineral-trioxideaggregate-repair-cement. Acessed in: February/2018

22. Ultradent Products, Inc. Products and Procedures Manual (2017) Repair Material: MTA Flow p. 54-57 
23. Valentim D, Bueno CRE, Marques VAS, Vasques AMV, Cury MTS, Cintra LTA, Dezan-Junior E (2017) Calcium hydroxide associated with a new vehicle: Psidium cattleianum leaf extracts. Tissue response evaluation. Braz Oral Res 31(43):1-8

24. Gomes-Filho JE, de Azevedo Queiroz IO, Watanabe S, da Silva Santos LM, Lodi CS, Okamoto R, Ervolino E, Dezan E Jr, Cintra LTA (2015) Influence of diabetes mellitus on tissue response to MTA and its ability to stimulate mineralization. Dent Traumatol 31:67-72

25. American Association of Endodontists (2013) New materials/ technologies position paper. American Association of Endodontists, Chicago

26. Chhabra A, Teja TS, Jindal V, Singla MG, Warring K (2011) Fate of extruded sealer: a matter of concern. J Oral Health Comm Dent 5(3):168-172

27. International Organization for Standardization. Dentistry - preclinical evaluation of biocompatibility of medical devices used in dentistry. Test methods for dental materials: ISO/TR 7405-1997(E). Switzerland: ISO, 1997

28. Gomes-Filho JE, de Moraes Costa MT, Cintra LT et al (2010) Evaluation of alveolar socket response to Angelus MTA and experimental light-cure MTA. Oral Surg Oral Med Oral Pathol Oral Radiol Endod 110:93-97

29. Holland R, Souza V, Nery MJ, Otoboni-Filho JA, Bernabé PFE, Dezan-Júnior E (1999) Reaction of rat connective tissue to implanted dentin tubes filled with mineral trioxide aggregate or calcium hydroxide. J Endod 25(3):161-166

30. Cintra LT, de Moraes IG, Estrada BP et al (2006) Evaluation of the tissue response to MTA and MBPC: microscopic analysis of implants in alveolar bone of rats. J Endod 32:556-559

31. Gomes-Filho JE, de Moraes Costa MM, Cintra LT et al (2011) Evaluation of rat alveolar bone response to Angelus MTA or experimental light-cured mineral trioxide aggregate using fluorochromes. J Endod 37:250-254

32. Gomes-Filho JE, Watanabe S, Lodi CS, Cintra LT, Nery MJ, Otobon Filho JA et al (2012) Rat tissue reaction to MTA FILLAPEX. Dent Traumatol 28(6):452-456
33. Silveira CM, Pinto SC, Zedebski Rde A et al (2011) Biocompatibility of four root canal sealers: a histopathological evaluation in rat subcutaneous connective tissue. Braz Dent J 22:21-27

34. Camilleri J (2008) Characterization of hydration products of mineral trioxide aggregate. Int Endod J 41:408-417

35. Sarkar NK, Caicedo R, Ritwik P, Moiseyeva R, Kawashima I (2005) Physicochemical basis of the biologic properties of mineral trioxide aggregate. J Endod 31:97-100

36. Tay FR, Pashley DH, Rueggeberg FA, Loushine RJ, Weller RN (2007) Calcium phosphate phase transformation produced by the interaction of the Portland cement component of white mineral trioxide aggregate with a phosphate-containing fluid. J Endod 33: $1347-1351$

37. Gandolfi MG, Taddei P, Tinti A, Prati C (2010) Apatite-forming ability (bioactivity) of ProRoot MTA. Int Endod J 43:917-929

38. Camilleri J (2015) Mineral trioxide aggregate: present and future developments. Endod Top 32:31-46

39. Parirokh M, Torabinejad M (2010) Mineral trioxide aggregate: a comprehensive literature review_part III: clinical applications, drawbacks, and mechanism of action. J Endod 36:400-413

40. Marciano MA, Guimarães BM, Amoroso-Silva P, Camilleri J, Hungaro Duarte MA (2016) Physical and chemical properties and subcutaneous implantation of mineral trioxide aggregate mixed with propylene glycol. J Endod 42:474-479

41. Hsieh SC, Teng NC, Lin YC, Lee PY, Ji DY, Chen CC, Ke ES, Lee SY, Yang JC (2009) A novel accelerator for improving the handling properties of dental filling materials. J Endod 35:1292-1295

42. Guimarães BM, Vivan RR, Piazza B, Alcalde MP, Bramante CM, Duarte MAH (2017) Chemical-physical properties and apatiteforming ability of mineral trioxide aggregate flow. J Endod 43(10):1692-1696

43. Komabayashi T, Spångberg LSW (2008) Comparative analysis of the particle size and shape of commercially available mineral trioxide aggregates and Portland cement: a study with a flow particle image analyzer. J Endod 34:94-98 